\title{
Study of the Influence of Main Parameters of the Regenerator Ginning Machine on the Qualitative Indicators of the Fibers and Seeds
}

\author{
Azimjon Parpiyev ${ }^{1}$, Ilkhom Sabirov ${ }^{1}$, Alisher Usmankulov ${ }^{2 *}$, Nodir Navruzov ${ }^{1}$ \\ ${ }^{1}$ Tashkent Institute of Textile and Light Industry, 100100 Tashkent, Uzbekistan \\ ${ }^{2}$ Jizzakh Polytechnic Institute, 130100 Jizzakh, Uzbekistan
}

\begin{abstract}
Since cotton ginning in Uzbekistan is carried out mainly by saw gins, this article proposes a technology for the process of cotton ginning, regeneration, and purification of fibrous waste. The process of regeneration and purification of fibrous waste is an urgent problem for the cotton ginning industry since the composition of fibrous waste contains about $80 \%$ of spun fiber. Technology "The process of separating the fiber from seeds" was carried out in two stages: in the first stage of separating the fiber from seeds, a low density of the raw roller of the saw gin took place, while the productivity remained unnamed. After the first stage of separating the fiber from the seeds, the fiber was cleaned in fiber cleaners. The fibrous waste separated in the fiber cleaner was mixed with the seeds after the first stage of separating the fiber from the seeds and fed to the second stage of separating the fiber from the seeds. This paper proposes a technology for the regeneration and purification of fibrous waste, separated during fiber purification. The influence of the length of the seed comb pegs when ginning a mixture of progressed seeds and fibrous waste on gin using the 1DR-119 regenerator on the gin parameters and the quality of the resulting fiber has been studied. A diagram of an experimental technological process is proposed and the results of production tests carried out at "JSC Dalverzin Buttermilk Cleaning" are presented. Experimental dependences of productivity, quality indicators of fiber, and seeds on the length of the splitting of the seed comb were obtained. In this case, the length of the pegs of the seed comb was studied in the aisles from 95 to $125 \mathrm{~mm}$. The results of the experiments showed that with the lengthening of the heads of the seed comb, the residence time of the seeds in the working chamber increases, which entails a slight decrease in productivity and an increase in the share of short fiber in the product, but when the length of the heads of the seed comb is $125 \mathrm{~mm}$, lint prevails in the mass of fibrous products. Having a lower specific gravity compared to fiber, causing a decrease in the seed throughput of the regenerator gin. Analyzing the results of studies of the effect of the length of the pegs on the quality indicators of fiber and seeds after the second stage of ginning, it was revealed that with a decrease in the pubescence of the seeds emerging from the working chamber, their mechanical damage increases, which leads to an increase in the fiber of broken seed and such a hard-to-remove defect as a peel with fiber. Based on the research results obtained during processing on the 1DR-119 regenerator gin of a mixture of ginned seeds with the fibrous waste of fiber cleaners at different lengths of the seed comb splints, the most acceptable length of the seed comb is $105-115 \mathrm{~mm}$, since this produces a standard fiber with a staple mass length of $30.1-29.9 \mathrm{~mm}$, meeting the standards.
\end{abstract}

\section{Introduction}

The main task of the technology of primary processing of raw cotton is the production of cotton fiber, linters, and other products that are competitive in the world cotton market.

The competitiveness of cotton fiber in the world market is mainly ensured by the length of the fiber, its appearance, the content of defects, and trash impurities. In this regard, in recent years, the main emphasis in the technological process of processing raw cotton has been placed on ensuring the maximum preservation of the fiber length, improving its appearance, and reducing the content of defects and trash.

In the process of processing raw cotton according to the technological transitions of ginneries, vices and trash impurities are released into the waste with a simultaneous loss of the fibrous part, reaching $60 \%$ of the total mass of waste [1].

\footnotetext{
${ }^{*}$ Corresponding author: a.usmankulov68@gmail.com
} 
In raw cotton processing, one of the sources of fibrous mass losses is fiber cleaning during which fiber is cleaned along with the waste and mote. Regeneration and cleaning analysis showed that this process had a high impurity level and it was not reasonable to mix it with the mainstream of the manufactured fibers [2-6].

Hence, new technology for regeneration and cleaning of fibrous waste was offered and it consists of their mixing with ginned seeds and further ginning on regenerator ginning machine $[7,8]$. The process of the regenerator ginning machine is shown in Fig. 1.
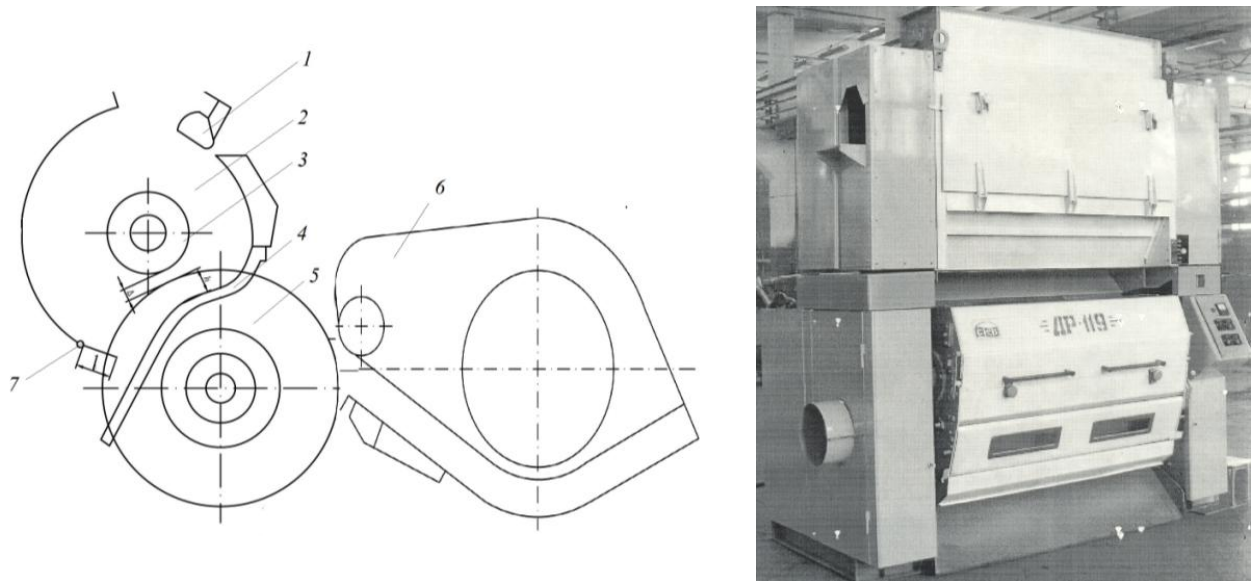

Fig. 1. Process diagram of the regenerator ginning machine: 1-guide; 2-working chamber; 3-speeder agitator; 4-bar grid; 5-saw cylinder; 6-air chamber; 7-seed grid

Different main parameters of regenerator ginning machine for secondary ginning of seeds with remained fibers can be found in the literature [9-13]. However, when mixing fibrous waste and ginned seeds, ginning conditions change. Simultaneous processes of free fiber seeds and mote fibers by the saw cylinder teeth and their pulling among the lowered seeds in the raw rolling pin, separation, and output from the working chamber take place.

The above-mentioned processes appear at particular values of the raw rolling pin density, if the density values of the raw rolling pin are little, fiber separation and cleaning do not happen. Thus, the best value of the raw rolling pin density should be defined which will provide the separation of the fiber from mote and waste impurities.

Stable operation of the regenerator ginning machine, withdrawal and staple mass, length of the manufactured fiber depend on parameters including length of the seed grid $(l)$, the value of the saw catch over the bar $(h)$, clearance between the speeder agitator and saw cylinder $(\Delta)$.

The article presents the results of the investigational study for defining the best length of the seed grid pike.

\section{Methods}

\section{Change after the first stage of ginning}

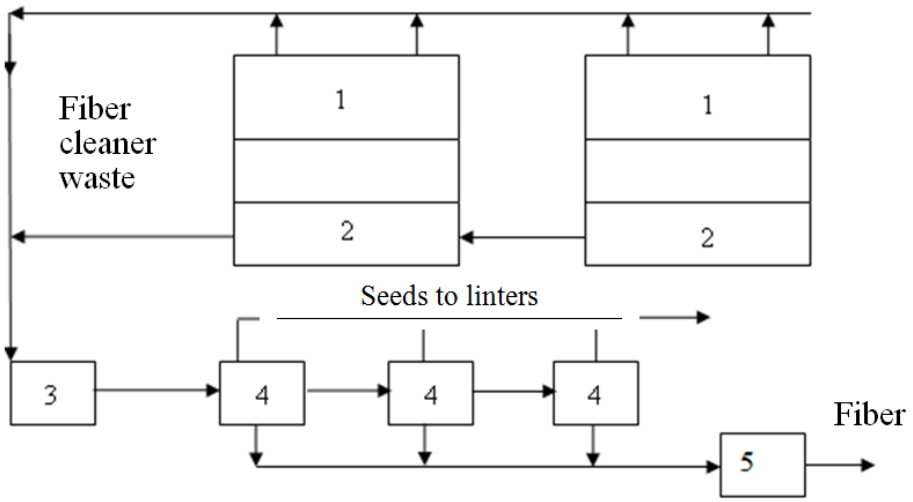

Fig. 2. Diagram of the experimental manufacturing process: 1 - saw ginning machines 5DP-130; 2 - fiber cleaning machines 2VPU; 3 - seeds elevating machine ES-14; 4 - regenerator ginning machines 1DR-119; 5 - condenser KL 
Investigational study for defining the influence of the length of the seed grid pike on the productivity of regenerator ginning machine 1DR-119 and qualitative indicators of seeds being processed with the fibrous waste and produced fiber was carried out under factory conditions at Dalvarzin Cotton Plant, in its main building where two saw ginning machines 5DP-130 combined with the fiber cleaning machine 2VPU, seeds elevating machine ES-14 and two regenerator ginning machines 1DR-119 and condenser KL are installed (see Fig. 2).

The research was carried out according to the specially developed methodology with the processing of raw cotton of An-Bayaut-2, III industrial grade, $2^{\text {nd }}$ class selection, with the source indicators being: humidity - $20.9 \%$, impurity $12.0 \%$, mote impurity $-0,5 \%$, mechanical damage of seeds $-0.2 \%$. Raw cotton had the following indicators on the tray of the ginning machine: humidity $-8.5 \%$, impurity $-1.8 \%$, mote impurity $-0.2 \%$, and mechanical damage of seeds $-1.9 \%$.

When rotation number was 8-9 $\min ^{-1}$ of power changer and operation of the ginning machine with the middle location of the seed grid, its productivity made $6.8-7.0 \mathrm{~kg}$ of fiber per a saw in an hour, lowness of the seed after ginning made $14.0-14.7 \%$, mechanical damage $-2.8-3.2 \%$.

Seeds processing on the second stage of ginning was carried out at regenerator ginning machines $1 \mathrm{DR}-119$ with the addition of fibrous waste from fiber cleaning machines, which had been transported by the screw from the first stage of ginning that is from the saw ginning machines 5DP-130 to elevator ES-14 (see Fig. 2).

During the experiment, the rotation speed of the saw cylinder of the regenerator ginning machine 1DR-119 made $730 \mathrm{~min}^{-1}$, while of speeder agitator $-500 \mathrm{~min}^{-1}$ and the catch of saws over the bar grin in the working part made 37 $\mathrm{cm}$, clearance between the speeder agitator and saw cylinder was $20 \mathrm{~mm}$, which was in accordance with the passport data of the regenerator ginning machine 1DR-119 [14, 15].

\section{Results and Discussions}

Table 1. Relation of productivity and qualitative indicators of fiber and seeds and pike length of the seed grid

\begin{tabular}{|c|c|c|c|c|c|}
\hline \multirow{2}{*}{ № } & \multirow{2}{*}{ Indicators } & \multicolumn{4}{|c|}{ Pike length of the seed grid, $\mathrm{mm}$} \\
\hline & & 95 & 105 & 115 & 125 \\
\hline \multirow[t]{3}{*}{1} & Seed after ginning, $\%$ : & & & & \\
\hline & - lowness & 14.5 & 14.3 & 14.2 & 14.0 \\
\hline & - mechanical damage & 2.9 & 2.8 & 2.8 & 3.0 \\
\hline \multirow[t]{11}{*}{2} & Fraction level of mote fiber, $\%$ : & & & & \\
\hline & - petiolule, stalk, large dirt & 0.2 & 0.2 & 0.2 & 0.2 \\
\hline & - little dirt & 15.0 & 14.8 & 14.5 & 14.9 \\
\hline & - nut's motes & 13.5 & 14.0 & 14.1 & 13.8 \\
\hline & - cut seeds & 5.0 & 5.1 & 5.0 & 5.0 \\
\hline & - fibrous part, total & 66.3 & 65.9 & 66.2 & 66.1 \\
\hline & Including: & & & & \\
\hline & - peel with fibers & 0.8 & 0.8 & 0.7 & 0.8 \\
\hline & - dirt & 1.4 & 1.4 & 1.5 & 1.3 \\
\hline & - free fibers & 64.1 & 63.7 & 63.9 & 63.9 \\
\hline & - staple mass-length, mm & 31.3 & 31.3 & 31.3 & 31.3 \\
\hline \multirow[t]{5}{*}{3} & Seeds after second regenerator ginning, $\%$ & & & & \\
\hline & - lowness & 14.1 & 13.6 & 12.8 & 11.8 \\
\hline & - mechanical damage & 3.4 & 3.6 & 3.7 & 4.3 \\
\hline & - impurity & 1.7 & 1.9 & 2.1 & 2.3 \\
\hline & - free fibers & 0.020 & 0.010 & - & - \\
\hline \multirow[t]{8}{*}{4} & Fibers after condenser KL, $\%$ : & & & & \\
\hline & Mass share of failures and impurities, total: & 10.4 & 11.3 & 12.9 & 15.0 \\
\hline & Including: & & & & \\
\hline & - large dirt & 2.4 & 2.3 & 2.3 & 2.3 \\
\hline & - little dirt & 4.1 & 4.0 & 4.0 & 4.0 \\
\hline & - motes & 2.2 & 2.2 & 2.2 & 2.2 \\
\hline & - cut seeds & 1.1 & 1.7 & 2.4 & 3.5 \\
\hline & - peel with fiber & 0.6 & 1.1 & 2.0 & 3.0 \\
\hline 5 & Staple mass-length, mm & 30.5 & 30.1 & 29.9 & 26.4 \\
\hline 6 & Fiber productivity, $\mathrm{kg} /$ machine hour & 51.0 & 61.0 & 82.0 & 75.0 \\
\hline 7 & $\begin{array}{l}\text { Seeds and fibrous waste mixing capacity, } \\
\mathrm{kg} / \mathrm{machine} \text { hour }\end{array}$ & 3256 & 3233 & 3209 & 2168 \\
\hline 8 & $\begin{array}{l}\text { Cleaning effect of register ginning machine, } \\
\%\end{array}$ & 71.0 & 68.9 & 64.3 & 58.4 \\
\hline
\end{tabular}


Averaged data retrieved during the experiments is presented in tables 1 and 2, while charts of qualitative changes of fiber and seeds depending on the pike length of the seed grid are shown in Fig. 3.

As shown in Table 1, damage and impurities of fiber in fiber cleaner waste after application of regenerator ginning machine decrease sharply, cleaning effect at the same time makes from 58.4 to $70.0 \%$, depending on the pike length of the seed grid.

When seeds were processed on regenerator ginning machine 1DR-119 after ginning mixed with the fiber cleaner waste and increase of the pike length of the seed grid from $105 \mathrm{~mm}$ to $125 \mathrm{~mm}$ was observed, seeds capacity decrease of the regenerator ginning machine, decrease of the lowness, increase of the mass share of failure and impurities in fiber and decrease of its staple mass-length was registered.

Moreover, information in Table 1 and chart in Figure 2 show that as the pike length of the seed grid increase from 95 to 115 , the seed capacity of the regenerator ginning machine decreases from 3209 to $2165 \mathrm{~kg} /$ hour which is quite explainable as the longer the pikes are, the shorter the distance from their top to the saw cylinder teeth is, which lead to lowering of seed grid capacity.

Table 2 drawn from Table 1 shows that the cleaning of little dirt and motes is not effective enough $(75.3$ and $84.1 \%$, accordingly) and it does not depend on the pike length of the seed grid.

Table 2. Dependence of the cleaning effect and fiber length on the pike length of the seed grid

\begin{tabular}{|c|c|c|c|c|c|c|c|c|c|c|c|c|}
\hline \multirow[t]{2}{*}{ № } & \multirow{2}{*}{ 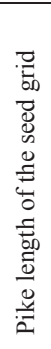 } & \multicolumn{2}{|c|}{$\begin{array}{c}\text { Fiber impurity } \\
\text { by the little } \\
\text { dirt, } \%\end{array}$} & \multirow{2}{*}{ 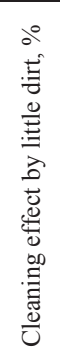 } & \multicolumn{2}{|c|}{$\begin{array}{c}\text { Fiber motes, } \\
\%\end{array}$} & \multirow{2}{*}{ 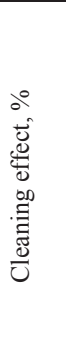 } & \multicolumn{2}{|c|}{$\begin{array}{c}\text { Mass share of } \\
\text { failures and } \\
\text { fiber impurities, } \\
\%\end{array}$} & \multirow{2}{*}{ 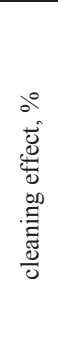 } & \multirow{2}{*}{ 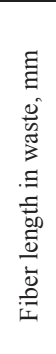 } & \multirow{2}{*}{ 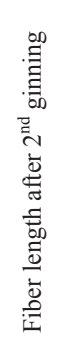 } \\
\hline & & 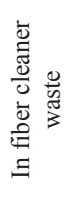 & 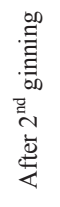 & & 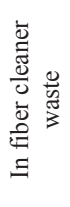 & 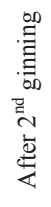 & & 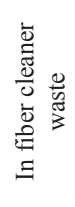 & 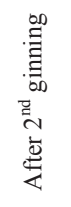 & & & \\
\hline 1 & 95 & 16.4 & 4.1 & 75.0 & 13.5 & 2.2 & 83.7 & 35.9 & 10.4 & 71.0 & 31.3 & 30.5 \\
\hline 2 & 105 & 16.2 & 4.0 & 75.3 & 14.0 & 2.2 & 84.3 & 35.5 & 11.3 & 68.2 & 31.3 & 30.1 \\
\hline 3 & 115 & 16.0 & 4.0 & 75.0 & 14.1 & 2.2 & 84.4 & 35.7 & 12.9 & 63.9 & 31.3 & 29.9 \\
\hline 4 & 125 & 16.2 & 4.0 & 75.3 & 13.8 & 2.2 & 84.1 & 35.2 & 15 & 57.4 & 31.3 & 26.4 \\
\hline
\end{tabular}

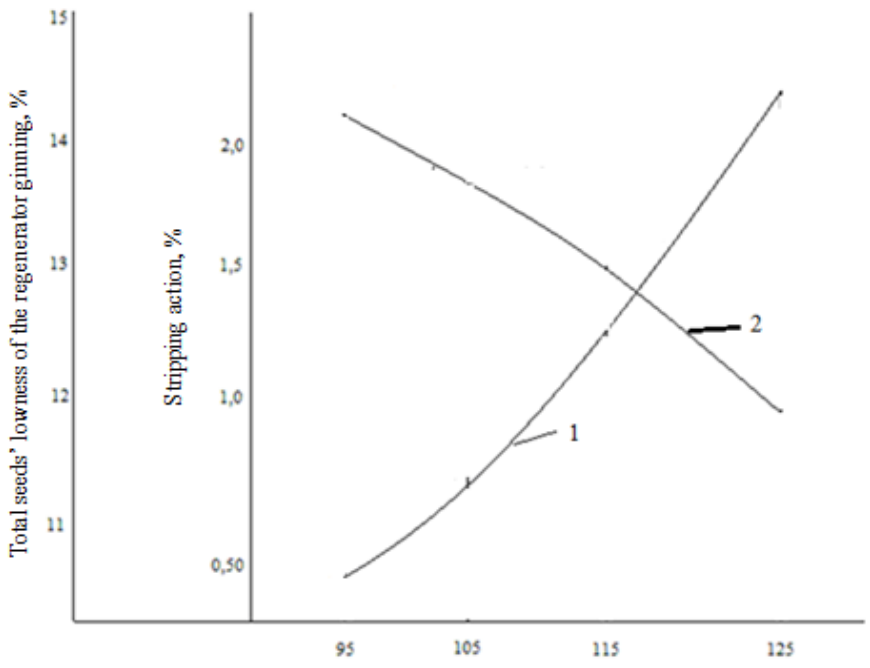

Pike length of the seed grid, $\mathrm{mm}$

1-stripping action; 2-total seeds' lowness

Fig. 3. Chart of the changes in stripping action and total seeds' lowness of the regenerator ginning machine

The cleaning effect by mass share of failures and impurities with increased length of pike decreases from $71.0 \%$ to $57.4 \%$, fiber length also decreases from 31.1 to $26.4 \mathrm{~mm}$. 
When analyzing fiber capacity, it should be noted that a particular pattern of its increase until the defined limit along with the extension of pike length of the seed grid is observed. Hence, if the pike length is increasing from 95 to 115 $\mathrm{mm}$, the productivity of the regenerator ginning machine increases from 51 to $82 \mathrm{~kg}$ per machine hour, while at pike length of $125 \mathrm{~mm}$, its sharp decline occurs until $75 \mathrm{~kg}$ per machine hour as seed productivity of the regenerator ginning machine 1DR-119 falls abruptly.

Consequently, with productivity increase, staple mass-length of the fiber slowly goes down from $30.5 \mathrm{~mm}$ to 29.9 $\mathrm{mm}$ if the pike length increases from 95 to $115 \mathrm{~mm}$ and sharply decreases until $26.4 \mathrm{~mm}$ if the pike length is 125 mm (see Fig. 4).

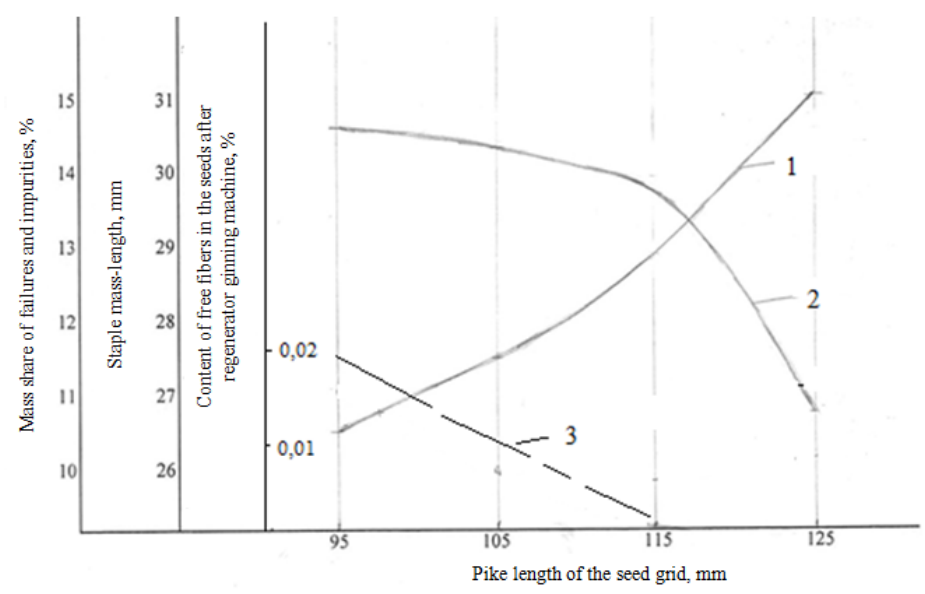

1-mass share of failures and impurities, \%; 2-staple mass-length of the fiber, $\mathrm{mm}$; 3 -content of free fibers in the seeds after regenerator ginning machine $1 \mathrm{DR}-119$

Fig. 4. Chart of changes of mass share of failures and impurities and staple mass-length of fiber depending on the pike length of the seed grid

This situation can be explained if refer to the consideration of the time of seeds being in the working chamber. Previous studies [16] showed that as the distance between the pikes of the seed grid and teeth of sawing cylinder decreased, the period of seeds being in the working chamber increased and the lint content in the fiber also went up. Depending on this statement, as the pike length of the seed grid increases, the time of seeds being in the working chamber also increases which means that lint content in the produced fiber grows; nevertheless, most fibers in the total mass of the fibrous product make long ones.

However, when the pike length of the seed grid reaches its critical limit, which in this case is $125 \mathrm{~mm}$, lint dominates in the total mass of the manufactured fibrous product that has lower volume weight compared with the fiber which leads to the decrease of seeds capacity of the regenerator ginning machine.

When analyzing other indicators provided in Tables 1 and 2, it should be noted that as the pike length of the seed grid increases, based on the statement presented above, the lowness of the seeds going out from the working chamber gradually decreases, which lead to the increase of the broken seeds in fiber and presence of such a problem failure as peel with fiber.

Statistical analysis of the experiment results gives adequate equations of stripping action regression $\left(\mathrm{Y}_{1}\right)$, seed lowness $\left(\mathrm{Y}_{2}\right)$ content of failures and impurities in fiber $\left(\mathrm{Y}_{3}\right)$ and staple mass-length of fiber $\left(\mathrm{Y}_{4}\right)$ from the length of seed grid, which is:

$$
\begin{aligned}
& Y_{1}=0,0015 \mathrm{x}^{2}-0,27 x+12,51 \\
& Y_{2}=0,0012 \mathrm{x}^{2}+0,187 x+7,17 \\
& Y_{3}=0,003 \mathrm{x}^{2}-0,505 x+31,4 \\
& Y_{4}=-0,011 \mathrm{x}^{2}+2,28 x-86,83
\end{aligned}
$$

\section{Conclusions}

Consequently, analysis of the data retrieved from the processing of mixture of ginned seeds on regenerator ginning machine 1DR-119 along with the fibrous waste from fiber cleaning machine provided the different length of seed grid pike show that the most acceptable length of the seed grid is $105-115 \mathrm{~mm}$ as at this length standard fiber with 
staple mass-length of 30.1-29.9 mm is produced which is in accordance with the governmental standard. Further extension of the pike length of the seed grid over $115 \mathrm{~mm}$ leads to the appearance of lint.

\section{References}

1. V.D. Khmirov, Development of regeneration technology of underpinned pappus of raw cotton before lending and creation of the device for its accomplishment, Candidate of Sciences Dissertation, Tashkent (1987)

2. H.Yu. Ulugmuradov, I.Z. Abbazov, R.M. Muradov, Study on improving the efficiency of cleaning the pile drum, IOP Conference Series: Earth and Environmental Science 614(1), 012127 (2020)

3. K.J. Djumaniyazov, I.Z. Abbazov, D.E. Kazakova,m Change of physical and mechanical indicators of yarn depending on the design of the sampling drum, Journal of Critical reviews 7(3), 411-415 (2020)

4. K Sabirov, Development of technology for high production stage ginning and linting, Doctor of Sciences Dissertation, Tashkent (2008)

5. F. Uddin, Introductory Chapter: Textile Manufacturing Processes, Textile Manufacturing Processes, IntechOpen (London 2019)

6. K. Sabirov, Influence of processing a mix of fiber waste and cotton on fiber quality indicators and output, Problems in Textile Industry 2, 94-96 (2006)

7. I.K. Sabirov, Processing technology of fibrous waste from fiber cleaners mixed before the second stage of ginning Collections of publications from RSAC, (Tashkent 2015)

8. I.K. Sabirov, New Technology for processing seed cotton of medium-staple cotton varieties, Digest of scientific and technical achievements in the Republic of Uzbekistan: 76th Plenary meeting of the International Uzbek cotton and Textile fair, Tashkent, Uzbekistan (2017)

9. A.Parpiyev, I.Q. Sobirov, N.A. Navruzov, Selection of basic parameters of gin - fiber waste regenerator, Science Research Development 15 (2019)

10. A.Parpiyev, N.A. Navruzov, The analysis of residual fibration of seeds after saw ginning, European Science Review 7-8, 246-251 (2018)

11. A. Parpiyev, N.A. Navruzov, Improvement of Saw Ginning, Int. J. Advanced Research in Science, Engineering and Technology 5, 9 (2018)

12. A. Parpiev, N.A. Navruzov, Residuality of seeds collected in Arrali demons, Innovative ideas and developments of talented youth in the conditions of cotton ginning, textile, light industry, modernization of printing technology, Tashkent (2018)

13. A. Parpiev, N.A. Navruzov, Study of the effect of mental labor productivity on residual fatigue, Scientific and Technical Journal of Textile Problems 4 9-15 (2018)

14. A. Parpiev, N. Navruzov, Residual tolerance analysis in cotton harvesting, International Conference on Problems of Increasing the Efficiency of Modern Production and Energy Efficiency, Andijan 110-113 (2018)

15. A. Parpiev, H. Pardaev, N. Navruzov, The impact of labor productivity and the condition of the seed comb on the residual yield in the seed, International Conference on Prospects for an Intensive Approach in the Period of Innovative Development, Namangan, 160-162 (2018)

16. N. Navruzov, Methodology for determining the structural composition of raw materials, Scientific and Technical Journal of Mechanics Problems 1, 46-50 (2018) 